\title{
Work-related factors affecting the retention of medical officers in the preventive healthcare sector of Sri Lanka
}

\author{
Mahendra Arnold ( $\triangle$ mahendra_arnold@yahoo.com ) \\ Ministry of Health Sri Lanka https://orcid.org/0000-0001-7746-8515

\section{Dinusha Fernando}

Regional Director of Health Services Offfice, Puttalum

\section{Kapila Wickramanayake}

Medical Supplies Division, Ministry of Health

\section{Palitha Karunapema}

Health Promotion Bureau, Ministry of Health

\section{Sepali Wickramatilake}

Regional Director of Health Services, Matale

\section{Yamuna Fernando}

Base Hospital, Panadura

Chandani Denawaka

MOH Office, Nugegoda

\section{Pasyodun Koralage Buddhika Mahesh \\ Ministry of Health}

\section{Sujeewa Panditharathna}

Regional Director of Health Services Office, Rathnapura

\section{Research}

Keywords: Retention, Recognition, Work Schedule, Remuneration, Responsibility

Posted Date: May 8th, 2020

DOI: https://doi.org/10.21203/rs.3.rs-21948/v2

License: (c) (i) This work is licensed under a Creative Commons Attribution 4.0 International License. Read Full License 


\section{Abstract}

Background: Human resources are the livelihood of all types of organizations. The biggest challenge that organizations are facing today is not only managing these resources but also retaining them. Preventive health sector plays a vital role in the healthcare system. Medical Officers of Health $(\mathrm{MOH})$ are the Medical Officers providing preventive health services in Sri Lanka. This study was carried out to explore the factors affecting retention of Medical Officers of Health in the preventive health sector in Sri Lanka.

Methods: A descriptive cross sectional study was carried out among Medical Officers of Health in the Colombo district which has $18 \mathrm{MOH}$ Offices with 64 Medical Officers. A pre-tested self-administered questionnaire was used as the study instrument. Data were analyzed using descriptive analysis, correlation and regression analysis.

Results: Regression analysis showed that all four variables; recognition, work schedule, remuneration and responsibility are positively and significantly correlated with retention of Medical Officers of Health in the preventive health sector. The variable 'work schedule' showed the highest impact to the retention of Medical Officers of Health.

Conclusions: In order to retain trained Medical Officers of Health in the Sri Lankan preventive health sector, health authorities should address the factors that influence retention. If policy makers fail to address these factors the preventive health services will be negative impact due to shortage of key service providers.

\section{Background}

Globally healthcare sector has been showing a dynamic change and improvement. Although being a developing country, has achieved very good health indicators compared to other similar settings. Certain indicators such as related to the control of vaccine preventable diseases are in par with developed countries. In Sri Lanka healthcare services are mainly provided by the government sector through healthcare institutions ranging from primary health care institutions to tertiary care hospitals. The healthcare service network is spread throughout the country and goes up to grass root level where domiciliary services are also provided [1].

Preventive healthcare service is considered as the backbone of the healthcare services in a country. The main emphasis of this healthcare system is to prevent diseases and thereby minimize the burden otherwise the curative sector would be subjected to. In Sri Lanka, preventive health services at the community level is provided by the Medical Officers of Health $(\mathrm{MOH})$ office. The entire country is covered by geographically demarcated Medical Officers of Health areas. Medical Officers of Health $(\mathrm{MOH})$ are the main medical staff in a $\mathrm{MOH}$ office. They are responsible for the preventive health services in their respective $\mathrm{MOH}$ area and play a vital role in preventing diseases and promoting health at the community level $[2,3]$. These services provided by the $\mathrm{MOH}$ office include: immunization for disease prevention, disease control programmes such as dengue, leptospirosis, malaria, filaria, maternal health services, child health services, services for youth and elderly, school health services, food safety, environmental health services, occupational health services, well women services, prevention programmes for Non Communicable Diseases and health promotion etc. The function of the $\mathrm{MOH}$ area mainly depends on the performance of the $\mathrm{MOH}$ as they not only functions as service providers but also as a technical expert in preventive health, as supervisors and managers. 
Employee retention refers to the length of time employees stay with the organization [4]. Retention of productive employees is a major concern of Human Resource (HR) professionals and business executives. It is more efficient in the system's perspective to retain a quality employee than to recruit, train and orient a replacement employee of the same quality [5,6]. Retention of human resources in the healthcare system, particularly doctors at district level is a great challenge faced by the decentralized health systems in poorly-resourced countries [7].

There are several predictors of a medical officer's willingness to retain in the preventive healthcare sector. It is a common belief that remuneration is one of the most important determinants of job retention. An attractive compensation package plays a critical role in retaining the employees $[8,9,10,11]$. Recognition is considered as one of the most important factors among non -financial rewards to increase retention of employees. It is used to strengthen the relationship between organization and people. Through the recognition employee feel rewarded and motivated [12.13]. Recognition can be described as the process where employees are rewarded in organizations by different status [14]. Intrinsic rewards like recognition, growth, feedback, opportunities lead employees more towards high job performance and motivation than extrinsic rewards like salary $[15,16]$. The amount of responsibility placed on the employee can have either negative or positive effects on employeeretention $[17,18]$. Doctors have different work schedules depending on their place of work and the work schedule has a big impact on their retention $[19,20]$.

In Sri Lanka the curative health sector is preferred by medical officers. Preventive health sector has become seemingly less attractive and medical officers in the preventive health sector tend to leave to the curative health sector. The number of applicants for preventive health posts are low compared to curative health sector posts. For an example, in the Colombo Regional Director of Health Services area which include the administrative capital of the country, at the end of 2018 of the approved cadre of 86 Medical Officer of Health, there were only 74 attached to $\mathrm{MOH}$ Offices. Of these $74 \mathrm{MOH}, 12 \mathrm{MOH}$ have applied/requested transfers to curative care institutions for the year 2019 under the 2019 annual transfers. This can potentially results in shortage of $\mathrm{MOH}$. If $\mathrm{MOH}$ are not retained in the preventive health sector there would be a vacuum created and it would be improbable to maintain quality preventive health services at the divisional level.. This would ultimately cause a major negative impact on the entire healthcare system.

This study was done to explore the factors affecting retention of Medical Officers of Health in the preventive health sector in Sri Lanka.

\section{Methods}

A descriptive cross-sectional study was conducted. The study population consisted of all 74 Medical Officers of Health in the preventive health sector attached to all $18 \mathrm{MOH}$ Offices in the Regional Directorate of Health Services in Colombo district of Sri Lanka. Medical Officers of Health who have not completed six months of service period were excluded since the officer would have not been sufficiently exposed to possible factors affecting work related factors in a shorter period.

Through review of literature, recognition, work schedule, remuneration, and responsibility were selected as factors affecting medical officers in the preventive health sector. A 25 item questionnaire was prepared with expert inputs to measure these four domains and the MOHs' willingness to retain in the preventive health sector. Primary data was collected through a pre-tested self-administered questionnaire. Pre-testing was carried out 
involving $10 \mathrm{MOH}$ working in $\mathrm{MOH}$ Offices in the Puttalum district. The internal consistency of the questionnaire was found to be satisfactory in the pre-test $[21,22]$. A coding system was adopted to conceal the identity of the respondent and hence the free expression of participants' actual attitudes and opinions was facilitated.. This improved the overall response rate and the response rates for each variable.

Domain scores were calculated for the willingness for retention, recognition, renumeration, work schedule and responsibility. Correlation analysis was be carried out to see the association between these domain scores with non-parametric correlation coefficient analysis. Following hypotheses on retention of medical officers in the preventive health sector were formulated

$\begin{array}{lll}\mathrm{H} 1 & : & \text { Positive and significant relationship exists between recognition and retention } \\ \mathrm{H} 2 & : & \text { Positive and significant relationship exists between work schedule and retention } \\ \mathrm{H} 3 & : & \text { Positive and significant relationship exists between remuneration and retention } \\ \mathrm{H} 4 & : & \text { Positive and significant relationship exists between responsibility and retention }\end{array}$

Multicollinearity was assessed by Variance Inflation Factor (VIF) and Tolerance Statistics. Multivariate analysis done with multiple linear regression. Ethical approval was obtained from the Ethics Review Committee of the National Institute of Mental Health, Sri Lanka.

\section{Results}

The questionnaire was administered to all 74 eligible medical officers and 64 responded with a response rate of $86.5 \%$. Out of the respondents, majority (62.5\%) were males. Nearly half of the participants (i.e. $48.4 \%$ ) were between 31 to 40 years of age. The commonest (of $26.6 \%$ of participants) total service period was between 6 to 10 years.

Correlation analysis was performed to assess the correlations between the independent and dependent variable (i.e. retention) as shown in Table 1.

The correlation coefficients of 'recognition', 'work Schedule', 'remuneration' and 'responsibility' showed positive relationships and were statistically significant. The strongest positive significant association was shown between 'recognition and retention' with a coefficient of 0.547 at a 0.001 significant level. $(r=0.547, p<0.001)$. A positive and statistically significant correlation exists between 'responsibility and retention' $(r=0.487, p<0.001)$, 'remuneration and retention' ( $r=0.439, p<0.001)$, 'work schedule and retention' $(r=0.422, p=0.001)$.

The VIF values were below 5 and tolerance statistics are above 0.4. The findings indicated non-existence of multicollinearity within the data (Table 2).

The regression analysis reveals the regression coefficients of 'recognition', 'work schedule', 'remuneration' and 'responsibility' are statistically significant. The regression analysis shows the highest magnitude of 1.039 represents the 'work schedule'. It indicates that a positive relationship between work schedule and retention in the preventive health sector. This is significant at 0.01 level. The second highest magnitude of 0.564 is for Recognition and it is significant at a 0.01 level. This indicates that there is a positive relationship between recognition and retention. A magnitude of 0.535 is seen for Remuneration and is significant at 0.01 level. This 
indicates a positive relationship between remuneration and retention. Responsibility showed a magnitude of 0.440 and is statistically significant at 0.01 level. This reveals a positive relationship between responsibility and retention.

\section{Discussion}

This is the first documented study exploring impact of work related factors on retention of medical officers in the preventive health sector in Sri Lanka. Based on the results from correlation analysis, it showed that there is a positive relationship between selected independent variables (Recognition, Work Schedule, Remuneration and Responsibility) and dependent variable Retention. Among four independent variables the strongest positive significant association was seen between Recognition and Retention with a coefficient of correlation of 0.547 at a 0.001 significant level. $(r=0.547, p<0.001)$. Regression analysis showed that highest magnitude (1.039) represents the work schedule. All four variables showed a positive relationship with retention in the preventive health sector and was significant at 0.01 level. The use of a correlational design and multivariate analysis aided in the development of new knowledge and forming hypotheses that could be used to inform further research.

The current study provided support on the positive and significant relationship between compensation and job retention documented in studies by Mabaso [10] and Chaulagain [11]. However, the findings were not in line with the study by Judge [8] where correlation between pay and job retention did not significantly correlate. Nel et al [15] indicated that intrinsic rewards like recognition lead employees more towards high job performance, motivation and retention. The findings of the current study supported this as positive and significant relationship existed between recognition and retention.

A study by Ning [18] among 650 full-time nurses employed in six Chinese hospitals on factors related to job retention showed that amount of work responsibility was a factor contributing for low retention. In contrast, the current study showed a positive and significant correlation between responsibility and retention. This may be due to the facts the studies were on two different staff categories and medical officers are specifically trained and required to take a higher level of responsibility compared to other health staff categories. In a study by Yaseen [20] on factors affecting doctors retention level, showed that not getting proper work schedule/structure was one of the main factors affecting retention. The current study revealed that there was a positive and significant association between work schedule and retention of medical officers. This indicates that the medical officers are satisfied with the current work schedule in the preventive health sector.

It is generally perceived among the medical officers that, medical officers in the curative sector draw a higher financial gain than the medical officers in the preventive sector due to the additions like higher extra-duty payments and holiday-payments. The satisfaction level of medical officers with regard to the variable 'remuneration' was lower than the other three independent variables studied. The $\mathrm{MOH}$ have a lower probability of working on holidays except during special programmes like dengue control programmes scheduled on public holidays. However, it is not a regular occurrence. Due to non-availability of night duties and on-call duties the amount earned as extra-duty payment is also potentially less. Unlike the medical officers in the curative sector, $\mathrm{MOH}$ being field officers are entitled to travelling and subsistence allowance. However, these allowances have very low monitory value and have not been revised for many years in line with the current cost of travelling. The health authorities should take serious note of this fact and revise the rates of overtime and other allowances in the preventive health sector to be in par with the payments in the other sectors.

Page 5/9 
There were limitations of the study. Data collection from medical officers was difficult due to their busy work schedules and having to collect data in a setting such as clinics where patient care is given. This may have contributed to the observed non-response rate. The study was conducted in the Colombo district. There are many geographical, cultural and economic variability in different districts in Sri Lanka which can influence the factors studied. Hence, the findings cannot be generalized to the entire country.

\section{Conclusions}

Work related factors: 'recognition', 'work schedule', 'remuneration' and 'responsibility' have a positive effect on willingness of medical officers to retain in the preventive health sector in Sri Lanka. Among four factors, the work schedule showed the highest impact to the retention of Medical Officers of Health. The policy makers in the Ministry of Health of Sri Lanka must take measures to create favourable contexts related to these factors in order to improve retention of Medical Officers of Health in the preventive health sector.

\section{Declarations}

\section{Availability of data and materials}

The datasets used and/or analysed are available from the corresponding author on reasonable request.

\section{Ethics approval and consent to participate}

Ethical approval was obtained from the Ethics Committee of the National Institute of Mental Health

\section{Consent for publication}

Not applicable

\section{Competing interests}

The authors declare that they have no competing interests.

\section{Funding}

The study was self-funded and was not funded by a third party.

\section{Authors' contributions}

SMA was involved in the conceptualization of the study, data collection, data analysis and drafting of the initial manuscript. CJD, RMSDF, HMKW, WYJF and MSKW were involved in data collection, data entering and manuscript writing. PKBM, RPPK and NGSP revised the manuscript. All authors read and approved the final manuscript.

\section{Acknowledgements}

Not applicable

\section{Authors' information}


Author details 1. Quarantine Unit, Ministry of Health, Sri Lanka. 2. Office of Regional Director of Health Services, Puttalam, Sri Lanka. 3. National Institute of Mental Health, Sri Lanka. 4. Health Promotion Bureau, Sri Lanka. 5. Office of Regional Director of Health Services, Matale, Sri Lanka. 6. Base Hospital, Panadura, Sri Lanka. 7. Office of Medical Officer of Health, Battaramulla. 8. Ministry of Health, Sri Lanka. 9. Office of Regional Director of Health Services, Rathnapura. Sri Lanka.

\section{Abbreviations}

$\mathrm{MOH}$ - Medical Officer of Health

\section{References}

1. Ministry of Health, Sri Lanka. National health strategic master plan 2016-2025, Health Administration and human resource for health. 2016.

http://www.health.gov.lk/moh_final/english/public/elfinder/files/publications/HMP2016-

2025/Health\%20\%20Admin\%20-\%20\%20HRH.pdf. Accessed 15 Mar 2020.

2. Fernando, DN. Healthcare system in transition, An overview of Sri Lanka's healthcare system. Journal of Public Health Medicine. 1997; 22(1):14-20.

3. Ministry of Health, Nutrition and Indigenous Medicine, Sri Lanka. Annual Health Bulletin - 2015. 2017. http://www.health.gov.lk/moh_final/english/public/elfınder/files/publications/AHB/2017/AHB\%202015.pdf. Accessed 15 Mar 2020.

4. Cappelli P. A market-driven approach to retaining talent. Harvard Business Review. 2000. https://hbr.org/2000/01/a-market-driven-approach-to-retaining-talent. Accessed 18 Mar 2020.

5. Society for Human Resource Management. Managing for Employee Retention. https://www.shrm.org/resourcesandtools/tools-andsamples/toolkits/pages/managingforemployeeretention.aspx. Accessed 13 Mar 2020.

6. Huang IC, Lin HV, Chuang $\mathrm{CH}$. Constructing factors related to worker retention. International Journal of Manpower. 2006;27(5): 491-508.

7. Sirili N, Frumence G, Kiwara A, Mwangu M, Anaeli A, Nyamhanga T, Goicolea I, Karin Hurtig Retention of medical doctors at the district level: a qualitative study of experiences from Tanzania. BMC Health Serv Res. 2018;18:260. doi: 10.1186/s12913-018-3059-0.

8. Judge TA, Piccolo RF, Podsakoff NP, Shaw JC, Rich BL. The relationship between pay and job satisfaction: A meta-analysis of the literature. J. Vocational Behav. 2010;77: 157-167. doi.

https://doi.org/10.1016/j.jvb.2010.04.002

9. Singha C, Singha R. Factors Affecting Employee Retention: A Comparative Analysis of two Organizations from Heavy Engineering Industry. European Journal of Business and Management. 2012;4(3): 145-162. file://C:/Users/user/AppData/Local/Temp/1324-2984-1-SM.pdf. Accessed 11 Mar 2020. 
10. Mabaso, CM, Dlamin, BI 2017, 'Impact of Compensation and Benefits on Job Satisfaction', Research Journal of Business Management. 2017; 11(2):80-90. doi:3923/rjbm.2017.80.90

11. Chaulagain, N, Khadka, DK. Factors influencing job satisfaction among healthcare professionals at Tilganga Eye Centre, Kathmandu, Nepal. International Journal of Scientific \& Technology Research. 2012;1(11):32-36.

12. Barton GM. Recognition at work. Scottsdale: World at Work. 2002: 51-55.

13. Romano L. Beyond reward: why cash is no longer enough. 2003;3(1)): 12-13.

14. Danish QD, Usman A. Impact of reward and recognition on job satisfaction and motivation: An empirical study from Pakistan. International Journal of Business \& Management. 2010;5(2):159-167.

15. Nel PS, Gerber PD, Van Dyk PS, Haasbroek GD, Schultz HB, Sono T, Werner A. Human Resources Management. Oxford University Press, Cape Town;2001.

16. Robbins SP, Judge TA. Organisational behavior. 15th ed. Pearson: USA; 2012.

17. Bardad SA. Factors influencing retention of essential healthcare providers at facility level in mandera county: a case study of mandera county referral hospital, Kenya. 2017. http://publications.universalhealth2030.org/ref/d15a4c64e07f02c7d1eec3314e2f951e. Accessed 14 Mar 2020

18. Ning S, Zhong H, Libo W, Qiujie L. The impact of nurse empowerment on job satisfaction. Journal of Advanced Nursing. 2009; 65(12):2642-8. doi: 1111/j.1365-2648.2009.05133.x

19. Tsai Y, Huang N, Chien L, Jen H, Chiang J, Chiou S. Work hours and turnover intention among hospital physicians in Taiwan: does income matter?. BMC Health Serv Res. 2016,16: doi. https://doi.org/10.1186/s12913-016-1916-2.

20. Yaseen, A. Effect of Compensation Factors on Employee Satisfaction- A Study of Doctor's Dissatisfaction in Punjab. International Journal of Human Resource Studies. 2013;3(1):142-157. doi: https://doi.org/10.5296/ijhrs.v3i1.3351

21. Lavrakas PJ. Cronbachs Alpha. Encyclopedia of Survey Research Methods. 2008, doi: http://dx.doi.org/10.4135/9781412963947.

22. Nunnally JC. Psychometric theory. 2nd ed. New York: McGraw-Hill; 1978

\section{Tables}

Table 1: Correlation matrix between attitude scores with spearman correlation coefficient 


\begin{tabular}{llllll}
\hline & Recognition & Work schedule & Remuneration & Responsibility & Retention \\
\hline Recognition & $\mathrm{r}=1.00$ & $\mathrm{r}=0.369^{*}$ & $\mathrm{r}=0.493^{*}$ & $\mathrm{r}=0.615^{*}$ & $\mathrm{r}=0.547^{*}$ \\
& $\mathrm{p}=\mathrm{NA}$ & $\mathrm{p}=0.003$ & $\mathrm{p}<0.001$ & $\mathrm{p}<0.001$ & $\mathrm{p}<0.001$ \\
\hline Work schedule & $\mathrm{r}=0.369^{*}$ & $\mathrm{r}=1.00$ & $\mathrm{r}=0.563^{*}$ & $\mathrm{r}=0.300^{*}$ & $\mathrm{r}=0.422^{*}$ \\
& $\mathrm{p}=0.003$ & $\mathrm{p}=\mathrm{NA}$ & $\mathrm{p}<0.001$ & $\mathrm{p}=0.016$ & $\mathrm{p}=0.001$ \\
\hline Remuneration & $\mathrm{r}=0.493^{*}$ & $\mathrm{r}=0.563^{*}$ & $\mathrm{r}=1.00$ & $\mathrm{r}=0.302^{*}$ & $\mathrm{r}=0.439^{*}$ \\
& $\mathrm{p}<0.001$ & $\mathrm{p}<0.001$ & $\mathrm{p}=\mathrm{NA}$ & $\mathrm{p}=0.015$ & $\mathrm{p}<0.001$ \\
\hline Responsibility & $\mathrm{r}=0.615^{*}$ & $\mathrm{r}=0.300^{*}$ & $\mathrm{r}=0.302^{*}$ & $\mathrm{r}=1.00$ & $\mathrm{r}=0.487^{*}$ \\
& $\mathrm{p}<0.001$ & $\mathrm{p}=0.016$ & $\mathrm{p}=0.015$ & $\mathrm{p}=\mathrm{NA}$ & $\mathrm{p}<0.001$ \\
\hline Retention & $\mathrm{r}=0.547^{*}$ & $\mathrm{r}=0.422^{*}$ & $\mathrm{r}=0.439^{*}$ & $\mathrm{r}=0.487^{*}$ & $\mathrm{r}=1.00$ \\
& $\mathrm{p}<0.001$ & $\mathrm{p}=0.001$ & $\mathrm{p}<0.001$ & $\mathrm{p}<0.001$ & $\mathrm{p}=\mathrm{NA}$ \\
\hline
\end{tabular}

*Correlation is significant at the 0.01 level (2-tailed).

Table 2: Multicollinearity analysis among the four predictors

\begin{tabular}{|l|c|c|}
\hline Variable & \multicolumn{2}{|c|}{ Co-linearity Statistics } \\
\cline { 2 - 3 } & Tolerance & VIF \\
Table 3: Multiple linear regression analysis \\
\hline Recognition & 0.749 & 1.335 \\
\hline Work Schedule & 0.613 & 1.632 \\
\hline Remuneration & 0.551 & 1.815 \\
\hline Responsibility & 0.790 & 1.266 \\
\hline
\end{tabular}

\begin{tabular}{|l|c|c|c|c|c|}
\hline Variable & \multicolumn{2}{|c|}{ Unstandardized Coefficients } & Standardized Coefficients & t & \multirow{2}{*}{ Significance } \\
\hline & B & Std Error & Beta & & \\
\hline Recognition & 0.564 & 0.128 & 0.489 & 4.411 & 0.000 \\
\hline Work Schedule & 1.039 & 0.185 & 0.580 & 5.607 & 0.000 \\
\hline Remuneration & 0.535 & 0.121 & 0.489 & 4.418 & 0.000 \\
\hline Responsibility & 0.440 & 0.113 & 0.444 & 3.903 & 0.000 \\
\hline
\end{tabular}

